\title{
CORRESPONDENCE
}

Psychiatric ward rounds

J J Bradley, FRCPSYCH.

5 Misdiagnosis of amoebiasis

Advice on exercise

P H Fentem, мв..............4429

Computer confidentiality

R M Forrester, FRCP; P A Samet, PHD . . . 429

Menopausal therapy and endometrial

pathology

I L Craft, FRCs, and others......... 430

Home or hospital care for coronary

thrombosis?

P H M Carson, FRCP ; J Cox, MRCGP. . . . . 430

Metoclopramide in young children

J A Sills, MRCP, and E J Glass, MRCP.....4 431

Housing, health, and illness

F J G Lishman, MD; D S Pickup, мFсм,

and $S$ Mookerjee, мв.......... 431

Screening for breast cancer

$M$ Baum, FRCS; $M$ R Alderson, $M D$, and

Jocelyn O P Chamberlain, FFCM......441

Domiciliary oxygen

P Howard, FRCP, and H C Middleton, MRCP 432
Maintenance treatment of duodenal ulcer with cimetidine

W L Burland, $M B$, and others; C G Clark, FRCS, and J H Wyllie, FRCS......... 433

Efficacy of rubella vaccination

W J C Roberts, MB............ 433

Children who cannot read

R D Harland, MFCM; W R Russell, FRCP. . . 434

Hypostatic ulceration and male sex chromosomal anomalies

J Jancar, FRCPSYCH; H Forssman, MD, and

$\mathrm{L}$ Wallin, MD .............. 434

Depot fluphenazine and tardive dyskinesia A C Gibson, FRCPSYCH. . . . ....... 434

Prostaglandin $F_{2} \alpha$ and tumours of the female genital tract

W H Lee and others.

Schizophrenia and neurosis

M G Livingston, MB............ 435

Colonoscopy in the diagnosis of pseudomembranous colitis

K Seppälä, MD................435
Sulphinpyrazone and prevention of death after myocardial infarction K G Green, FRCP. . . . . . . ......... 435

Basal cell carcinoma in identical twins J Kaprio, MD, and L Teppo..........446 Lord Mayor Treloar Hospital, Alton

K R J de Belder, FRCs, and others........ 436 Negotiating rights for junior hospital doctors

J $\mathrm{N}$ Johnson, fRCs............4436

Private day cases and outpatient

diagnostic services

D E Bolt, FRCS.........

New consultant contract
D I H Smith, FFARCS.

Money for old rope

$S$ P Deacon, MB.....

Points from letters Allergic alveolitis (F S Mooney); Carbamazepine and heart block (D V Hamilton); Synovial cyst causing an inguinal mass (Charlotte Feldman); Treatment of vaginal candidosis (P D Simmons); Humidifier fever (G S Abbey); Dopamine dosage (J M Chapman and J R Davies); Treatment of axillary hyperhidrosis (G N Vernon).....447
Correspondents are urged to write briefly so that readers may be offered as wide a selection of letters as possible. So many are being received that the omission of some is inevitable. Letters must be signed personally by all their authors.

\section{Psychiatric ward rounds}

SIR,-It is salutary for those of us currently on the other side of the fence to read of the experience of your correspondent in "Personal View" (1 July, p 50) of psychiatric ward rounds.

Since reading a letter describing similar experiences in the British fournal of Psychiatry ${ }^{1}$ my colleagues and I have made some effort to examine whether less daunting, distressing, and humiliating ways may be found in which the therapeutic team can pool ideas and observations and plan treatments. Of course meetings can be and are held in the absence of the patient, each member of the team seeing the patient privately at other times, but we have concluded that there are positive advantages for the patient being present at such ward conferences (a more appropriate term than ward "round"). She may then actively participate in discussing her symptoms, treatment, plans, and prospects with all those involved in her care and in a sense becomes a member of the therapeutic team. Certainly with the increasing autonomy of professional groups-nurses, psychologists, social workers, occupational therapists, etc-it is clearly vital that diagnosis and management must be co-ordinated, and for better or worse the consultant, as the legally responsible medical officer, must be the one to do it. Thus it is his responsibility to make sure that the ward conferences are at best therapeutic and at worst not too distressing for the patient.

Fortunately I have not had to suffer admission to a psychiatric unit but can readily empathise with the feelings of your corres- pondent. The sense of loss of status and identity when confronted by a group of professionals (and students) who may be, or may be perceived to be, less well qualified than oneself and the problem of adjustment to communal life with different ethnic and social groups of varying ages and degrees of psychiatric illness must be terrifying for anyone not completely psychotic.

But surely the question to be asked is not whether ward conferences should be replaced but in what ways they may be conducted so that they cause minimal or no distress. Clearly the patients must be prepared for the event by doctors, nurses, and other patients. The courtesy with which they are received and leave the room, the arrangement of furniture, the introduction of staff by name and role can all go towards relieving anxiety and temper the sense that the patient is simply an object of professional curiosity. Free-for-all questioning or interrogation must obviously be avoided and reassurance that distressing topics can be discussed with individual members of the team privately after the conference should be given. In practice, however traumatic the experience of the conference may be for some, I am always amazed at how rejected and disappointed those who have not been seen by the team as a body are.

Professionals of any kind are, I fear, prone to lapse into insensitivity from time to time, and those of us whose profession is concerned with human suffering need to examine our attitudes constantly, particularly when we can become fascinated by the "case" and forget the person.

It has not escaped my notice that your correspondent with her "Personal View" may be identical with the writer of the letter to the British Fournal of Psychiatry (I note that both reported that they had been admitted to hospital for physiotherapy), but that in no way invalidates her observations and we must be grateful to her for them.

J J BRADLEY

Whittington Hospital,

London N19

${ }^{1}$ British fournal of Psychiatry, 1978, 132, 111.

$\varnothing$

Misdiagnosis of amoebiasis

SIR,-About two years ago a patient who had visited the tropics died in one of the hospitals of our district after a laparotomy for a suspected carcinoma of the caecum. The patient proved to have amoebiasis. Amoebae had been looked for by conventional methods but not found.

The diagnosis of amoebiasis is notoriously difficult to confirm. It is particularly difficult where clinicians and pathologists have little personal experience of the disease. Our experience compels us to support the contention of Air Vice-Marshal Stamm ${ }^{1}$ that the disease should be considered in all patients with diarrhoea of more than two weeks' duration and in all patients with liver disease whose cause is otherwise obscure. We hope that further tragedies may be avoided by making wider use of the fluorescent antibody tests for amoebiasis.

We urge the Department of Health to make the tests freely available; to give them wide publicity; and to warn hospital doctors that 
the courts may take the gravest possible view of a failure to diagnose this treatable condition.

T H FOLEY

J L PRICE

St Luke's Hospital,

HeLEN Foley

Guildford, Surrey Stamm, W P, fournal of the Royal College of Physicians,
1975-6, 10,294.

\section{Advice on exercise}

SIR,-In “Any Questions ?” (1 July, p 49) your expert provides advice for a 60 -year-old man with essential hypertension, well controlled by propranolol, who is keen to improve his fitness by jogging or bicycling. It is likely that the publicity given to exercise by the media and the Health Education Council will lead to many similar requests for advice. Both the question and the published answer require comment.

Jogging and bicycling are referred to as "heart-lung exercises." This could be taken to mean that regular exercise has a direct effect on the function of the heart and lungs. Until recently this was the commonly held view. There is no direct effect on pulmonary function and a smaller direct effect on cardiac function than was previously thought to be so. In a number of elegant experiments it has been demonstrated that if a subject, by regular exercise, selectively trains one pair of limbs or one leg alone the improvement in general cardiovascular function usually seen with training is only evident during exercise involving the trained limb or pair of limbs. ${ }^{1}$ There is only a small improvement or none at all when the untrained limbs are used. Thus the primary change involved in the training process is local to the trained muscles-namely, improvements in the metabolic preparedness of the muscle cells ${ }^{3}$ and in the capillarity of the muscle. ${ }^{4}$ These adaptive changes in the cells of trained muscles ensure that the cells can extract the oxygen and other materials from a smaller volume flow of blood. Because there is a Iower muscle blood flow when an individual who exercises regularly uses trained muscles there is a reduction in the cardiac work required for exercise. In patients with cardiac disease the heart is also spared and there is an additional benefit because there is a smaller increase in cardiac output for a given amount of exercise. ${ }^{1}$ The overall effect apparent to the individual who trains is improved exercise tolerance, decreased fatigue, and increased work capacity.

It seems to follow from this account that advice regarding exercise must lay greater stress on the events taking place in the muscles. There is less point in setting target heart rates and sticking slavishly to these, although in certain circumstances they are a useful guide in normal individuals. The exercise must be sufficient to train muscles which the individual uses in everyday living; exercise which is greater than that to which they have now become accustomed will usually be sufficient. Indeed, levels of habitual physical activity in the population are so low that walking is sufficient to achieve a training effect in many individuals. Medical advisers will often be very much readier to counsel their patients to take regular exercise when they realise that this is the case. In any event jogging should not be attempted by the man described in the question until he has worked up to this by regularly walking for $\frac{1}{2}-1 \mathrm{~h}$ per day on at least four days per week for six weeks, or better for 12 weeks, and until it is clear that this amount of exercise does not cause untoward symptoms. Alternative bases for advice must be sought which do not depend upon pulse rate measurements.

Department of Physiology and
Pharmacology,
University Hospital and Medical
School,
Nottingham

P H FenteM

Clausen, J P, Physiological Reviews, 1977, 57, 779.
Saltin, B, Annals of the New York Academy of Sciences, 1977, 301, 224.

Sciences, 1977, 301, 224.
Holloszy, J O, Progress in Cardiovascular Disease, 1976, 18, 445.

Andersen, P, and Henriksson, J, fournal of Physiology, 1977, 270, 677.

Miller, N E, et al, Lancet, 1977, 1, 965.

Cumming, G R, and Glenn, J, Canadian Medical

Association fournal, 1977, 117, 346. Shepherd, R J, Canadian Medical Association fournal,

\section{Computer confidentiality}

SIR,-Drs P M Dunn and C H M Walker (22 July, p 276) make an eloquent plea for the computer in the storage of personal medical records. To me, however, their letter misses the point of the objections, which is thisthe sole reason for the use of the computer is that the data stored are easily retrieved. Written data in filing cabinets are clearly greatly at risk from the casual seeker for information, but in practical terms they are so difficult to extract that they are relatively safe. The easily retrieved data in a computer are "safe" so long as the keys are in the hands of people like Drs Dunn and Walker and their current colleagues, whose integrity is beyond question. But who knows who will be the next operators of this or other data banks? Surely we must be aware of the possibility of less well-motivated people edging their way now into key positions in the data banks ready to emerge with the answers when the time comes. Recent Russian experience suggests that doctors may be the subject of political pressure. The German anxieties about medical data have been revealed by Winton. ${ }^{1}$ They are too close to the memory of another totalitarian state for ease of mind.

I am a personal advocate of informationsharing among professionals, and especially so in the case of the sick or handicapped child, but this is a totally different issue from the data bank and its implications.

\section{R M FORRESTER}

Mary Sheridan Centre

Leigh Infirmary, Winton, $\mathrm{R} \mathrm{R}$, The Future of Professional Freedom.
London, CMF Publication, 1977.

SIR,-Absence from London has prevented me from writing earlier about the discussion at the recent ARM conference about the use of computers to handle medical records and the general opposition to such schemes (22 July, p 298).

It strikes me that such opposition is based mostly on emotion and ignorance rather than on sound facts. To demand security for medical records is unexceptionable, but to suggest that the present system of handwritten records in open folders gives even the most minimal protection is absurd. Anyone who has access to such a patient record has access to all of it without any difficulty.

Computer-based systems, on the other hand, can provide a great deal of security very easily. For a start, access can be limited to those who require it and permission may be granted for access only to parts of a file. For instance, the doctor may have access to the complete record but the pathology laboratory only to results of its own tests. It is easy to encode the stored information so that it is a meaningless jumble of symbols to anyone who steals it but so that it can all be displayed in a sensible way when needed.

As an example of a successful recordhandling scheme I would like to draw your readers' attention to the Exeter Community Health Services Computer Project. This is used by doctors in general practice and hospital, nurses, laboratory staff, and secretaries. This scheme, incidentally, won the British Computer Society's Award in 1977 for the project of most benefit to society. The degree of access to particular records is determined entirely by the doctor handling a case.

An argument sometimes used against the use of computers for handling personal data is the "danger" of combining information from several sources, either for statistical purposes or for record linkage of related cases. This is hardly a valid argument for medical records. Use of a national data base would allow the early and rapid detection of dangerous or urgent conditions and individuals at risk (thalidomide? epidemics? exposure to carcinogenic chemicals? organs for transplantation ?) in a way that is totally impossible by other methods. I believe most people would accept the socalled risks of computer-based record systems in return for the benefits they can bring.

Medical records are but one type of sensitive information that needs careful handling, in computers or by any other method. The problems of privacy and security have been studied and understood by many people for a long time. Unfortunately the reports I have seen of the BMA conference gave no indication that the medical profession is aware of this.

\section{Paul SAmet President,}

Computer Centre,

University College
London WC1

\section{Menopausal therapy and endometrial pathology}

SIR,-We read with interest the paper by $\mathrm{Mr}$ D W Sturdee and others (17 June, p 1575) on the incidence of endometrial hyperplasia occurring with different hormone preparations. Hyperplasia was reported in $12 \%$ receiving unopposed cyclical oral oestrogens and in $8 \%$ receiving an additional five-day course of an oral progestogen. It did not occur at all in those receiving cyclical oestrogens with additional progestogens for 10-13 days. Oestrogen implants with five days of oral progestogens each month were associated with the highest incidence, $28 \%$.

During the past 18 months we have been concerned about the long-term effects of unopposed oestrogens, particularly on the occurrence of endometrial hyperplasia and possible cancer formation. Because of this concern we have undertaken a pilot study to evaluate the efficacy of using combined 